\title{
La política turística en México desde el modelo de calidad total: un reto de competitividad
}

\section{Tourism policy in Mexico from the viewpoint of the total quality model: a competitiveness challenge}

IRMA M aGAÑA-CARRILLO*

\begin{abstract}
This article analyses the Mexican public policies focussed into tourism that, according to the development plans, have as a main objective to "make of M exico a competitive product for tourism". It is due to this fact that tourism enterprises look for devel opment under schemes of total quality control in order to enter the gl obal tourist markets. The aim of this study is to identify the areas of opportunity for M exico as a tourist destination, as well as to define proposals that improve the management and strategic planning of the Mexican tourism.
\end{abstract}

Keyw ords: tourism policy in Mexico, tourism public administration, total quality control, competitiveness, top management.

\section{Resumen}

En el presente artículo se analizan las políticas públicas mexicanas enfocadas al turismo que -según se desprende de los planes de desarroIlo- tienen como estrategia central hacer de M éxico un producto turístico competitivo. Es por esa razón que las empresas turísticas buscan desarrollarse bajo esquemas de control total de calidad, con la finalidad de posicionarse en los mercados turísticos globales. El objetivo de esta investigación es identificar las áreas de oportunidad que tiene M éxico como destino turístico, así como definir propuestas para mejorar la dirección y planeación estratégicas del turismo mexicano.

Palabras clave: política turística en M éxico, administración pública del turismo, control total de calidad, competitividad, alta dirección. 


\section{Introducción}

El presente artículo es el resultado de la investigación "Propuesta para implementar la cultura de servicio de calidad total en los negocios turísticos", definiendo las estrategias para presentar a M éxico como un destino turístico atractivo para el mercado AsiaPacífico y hacerlo un miembro más activo en la Pacific Asia Travel Association (PATA) en el siglo xxı, realizada en Japón durante los años 2001 a 2004. La investigación se enmarcó en la línea de "El modelo de servir con calidad total en el servicio".

Como tal, este artículo pretende explicar la falta de competitividad del producto turístico M éxico desde una de las perspectivas posibles: la ausencia de líneas de acción de la política turística mexicana que atienda el fortalecimiento de la cultura empresarial del sector privado desde la alta dirección, utilizando siempre -como enfoque en el análisis de las políticas- la filosofía del modelo de calidad total.

La investigación de la que se desprende este texto tuvo como objetivo general identificar los factores-componentes que forman una cultura de servicio de calidad total en los productos y servicios turísticos en Japón, en los ámbitos directivo y operativo; asimismo, propone el diseño e implementación de un modelo de servicio de calidad total para el sector turístico en M éxico e identificar las acciones necesarias para llevar a cabo una participación activa y productiva en la PATA.

Uno de los objetivos particulares fue analizar las políticas turísticas desde el marco del Plan Nacional de Desarrollo (PND) y su concepción en las diferentes acciones contempladas en los planes nacionales de turismo (PNT); con el fin de saber cuáles son las áreas de oportunidad y definir propuestas para mejorar el grado de competitividad del producto turístico México en los mercados mundiales.

Considerando la metodología que se utilizó para lograr los objetivos de este proyecto, se traza una estrategia basada en la siguiente pregunta de investigación: ¿qué estrategias necesita M éxico para implementar en su oferta turística un sistema de servicio de calidad total?

En este proyecto se propuso una metodología que combinó la aplicación de fuentes bibliográficas e instrumentos cualitativos (entrevistas en profundidad y observación participativa y no participativa). Estas técnicas se aplicaron a empresarios japoneses en el propio Japón, durante un periodo de tres años. 
Las variables que se seleccionaron son: satisfacción y expectativas del cliente externo, así como la lealtad de éste a sus proveedores. Se observó y midió en algunas unidades económicas japonesas -que son las más representativas de la actividad turística en M éxico- como: hoteles, restaurantes, bares, transporte, así como en operadoras y agencias de viajes (estas últimas se agregaron por su efecto en el mercado japonés).

Desde este enfoque, y con base en la investigación doctoral realizada, el presente artículo intenta un acercamiento al desarrollo de la actividad turística en el M éxico moderno, desde la política pública, mediante los planes nacionales de desarrollo y los programas nacionales de turismo llevados a cabo desde 1976, incluido el ahora Programa Sectorial de Turismo (PST) 2007-2012. Dicho acercamiento es la base que impulsó la investigación, por lo que se recupera en este texto para, a partir del enfoque del modelo de calidad total, intentar explicar y comprender el bajo perfil competitivo de M éxico como destino turístico.

Cabe señalar que el turismo es una actividad que en M éxico tiene una importancia vital por su aportación al producto interno y a la balanza de pagos. Esta relevancia también se refleja en la presencia del sector en los programas de desarrollo nacional, por lo que se hacen necesarias políticas públicas orientadas a lograr que nuestro país sea competitivo en los mercados turísticos mundiales.

Por ende, es importante analizar a M éxico en el contexto internacional turístico desde los resultados de la aplicación de las políticas públicas llevadas a cabo, ya que su papel de destino turístico implica, entre otras cosas, valorar lo que se ha hecho hasta ahora en esta materia. En este trabajo se aborda la historia del turismo reflejada en la estructura política nacional, desde que nace la política pública para el turismo en M éxico, en 1949.

A lo largo de este artículo se utiliza como fundamento los conceptos de gobierno y su efecto en el turismo; el de la política pública turística como eje de las acciones gubernamentales y el papel de la administración pública; en otro apartado se aborda la trascendencia de la figura de alta dirección en las empresas para, finalmente, presentar aspectos relacionados con la competitividad y sus distintos enfoques.

Las conclusiones de este texto se tratan a manera de experiencia reflexiva; y pretenden mostrar áreas de oportunidad específicas para la acción gubernamental, desde el ámbito legislativo, para la actividad turística en M éxico. 


\section{El gobierno y la política turística en M éxico: 1976-2012}

El gobierno juega un papel definitivo en el desarrollo de la actividad turística de M éxico, pues es quien tiene el poder de crear políticas públicas, así como el marco de acción legal y financiero que el turismo requiere para su desarrollo. Principalmente, el Estado puede proveer al turismo infraestructura y "puede igualmente controlar la 'industria' y sus actividades en virtud de lograr que las actividades y los estándares de seguridad se mantengan en el interés público" (Elliot, 1997: 4).

O tro papel importante del gobierno es el de generar la estructura administrativa para diseñar productos turísticos con base en insumos clave como: los recursos naturales y los hechos por el ser humano, las tradiciones, las costumbres, la gastronomía, el folklor, entre otros; además de que impulsa la promoción, el fomento al desarrollo, el financiamiento y el estudio del turismo. La administración es la estructura funcional que se requiere para hacer realidad palabras y promesas de políticos. El turismo, para que sea efectivo, no puede atenerse a declaraciones, programas y planes sin ningún soporte real de ejecución. La justificación de la administración pública en el turismo sólo es posible por medio de resultados, es decir, su práctica y desempeño deberá reflejar validación, legitimidad, profesionalismo, efectividad y eficacia.

Una más de sus responsabilidades, en el ámbito cultural, la señala Elliot, quien nos dice que el gobierno "está involucrado en el turismo no sólo viéndolo como industria lucrativa; sino también como experiencia educativa y cultural tanto para los turistas como para la comunidad receptora. El turismo no sólo tiene impacto económico, sino medioambiental y en la cultura local" (1997: 4). Los encuentros culturales que genera este sector provocan un aculturamiento, donde los participantes conviven y tratan de aceptarse, al tiempo que mezclan sus costumbres. También en este sentido debe actuar el gobierno, y no sólo por las ganancias económicas que genera el turismo, sino por los beneficios cualitativos que implica, a fin de tener un mejor efecto e imagen en el ámbito internacional como destino turístico: ser un país seguro, de fácil oferta para el cliente-turista del mundo.

La forma en que se administre el turismo dependerá de la propia cultura política del país y de la ideología de su gobierno. Elliot señala que "un gobierno será tan activo en el manejo del turismo, dependiendo de su ideología política y la importancia que le da a esta actividad" (1997: 17). Por ejemplo, para el caso 
M éxico, en el PNT 2001-2006 y en el PST 2007-2012 queda claro que hay un avance en las declaraciones del Poder Ejecutivo acerca de la importancia que representa esta actividad. Sin embargo, en sexenios anteriores se le dio poca atención a las declaraciones en beneficio de este sector.

Es importante señalar que, de acuerdo con Elliot (1997), gobierno se refiere a las instituciones y procesos mediante los cuales la sociedad puede tomar, imponer y hacer cumplir decisiones. La administración pública, por su parte, es responsable de dirigir organizaciones que busquen lograr los objetivos del gobierno, al igual que formular e implementar política pública. La administración pública participa en el sistema político y con la sociedad debido a que hay ciertos principios generales que se deben seguir y el gobierno es el responsable de implementarlos. Cuanto más se cumplan estos principios y en cómo se interpreten dependerá de la cultura política nacional y del gobierno (Elliot, 1997: 40).

Por su parte, para López Palomeque también queda claro que debemos comprender el papel de la administración pública en relación con el turismo: "La intervención de la administración pública en el sector turístico en el último medio siglo [... ], formalizado en lo que se denomina política turística, se ha ido adaptando a los factores condicionantes y a las diversas necesidades del sector [y a] la evolución y los cambios en la organización de la administración turística y en política turística durante las últimas décadas" (2004: 36).

El sistema político se entiende como un patrón persistente de relaciones humanas que implica, en gran medida, poder, dominio y autoridad. Q uienes detentan el poder poseen, entre otras, las capacidades para vencer una resistencia y para modificar el comportamiento de otros, o incluso de detenerlos, de obtener lo que ellos quieran. El poder determina quién obtiene qué, cuándo y cómo (Elliot, 1997).

Por tanto, entender que la política pública es útil para aplicar acciones que sigue un actor (o grupo de actores) para resolver algún problema o asunto de interés, deja en claro la relación con la administración pública y la importancia del gobierno en todos los sentidos. Éste ha demostrado interés por el turismo debido a los efectos económicos y los usos sociales que genera en la economía del país. Las creencias y valores ideológicos y filosóficos del sistema político definen el alcance de cada gobierno para intervenir en el sistema económico, en el papel del sector privado 
y, por ejemplo, en qué tanto soporte y financiamiento se le otorgará al turismo (Elliot, 1997).

J oseph I vars Baidal señala que "Ios planes no se implementan, las leyes y las políticas no se imponen y el desarrollo turístico no se controla, en parte por el fallo de las organizaciones gubernamentales administrativas" (2003: 19); lo que revela que el gobierno es irremplazable en la apropiada respuesta a las necesidades que el mismo sector demanda. Cabe, entonces, hacer hincapié no sólo en el cometido del gobierno en su participación en el turismo, sino que es necesario comprender conceptos como la política económica y, por ende, la política turística.

José Silvestre M éndez define la política turística como "un conjunto de acciones que realiza el Estado en materia turística con el fin de fomentar el turismo interno y externo y las actividades ligadas a éste" (1998: 35). Las políticas turísticas provienen de las políticas económicas, que se generan para marcar pautas de acción del gobierno en asuntos generales de nivel macro. La actividad turística no se puede aislar de un entorno económico, el cual es necesario para que exista en un mercado global.

Así, por medio de la política pública se establecen las acciones del gobierno en materia de turismo, haciéndolas posibles desde su misma estructura pública, que es la administración pública misma. Es importante señalar que cuando se toma la decisión de establecer una política turística, se debe contemplar -a un mismo tiempo- el organismo responsable de su ejecución, el cual "asumirá el diseño de las acciones que considere adecuadas para satisfacer, dentro de un orden de prioridades, las metas generales que acotan la política turística seleccionada" (WAHAB, 1992: 216).

Para que el turismo esté presente en un mercado se requiere que sea un producto; entonces, es necesaria la convergencia de otras actividades económicas; con esto se logra que la política turística contemple tal relación en todo su contexto, efectos y usos sociales. Sin embargo, debido a lo complejo de esa relación, la propuesta al Poder Legislativo de la política turística -en su mayoría- no es integral, con las consecuencias negativas que esto conlleva en las que quedan de manifiesto sus efectos y usos sociales, así como la desintegración de su esencia misma. López Palomeque reconoce que "las particularidades del sector turístico, en definitiva, lo hacen especialmente receptivo a numerosas políticas instrumentales. Resulta oportuno señalar que el turismo, como actividad económica receptora de divisas, de creación de riqueza y de empleo, está igualmente condicionado por otras 
políticas instrumentales, que [... ] permiten el logro de objetivos propios de políticas económicas finalistas, tal como sería el caso del equilibrio económico exterior" (2004: 13-14).

Por su naturaleza, el turismo requiere de una atención especial y cuidado en el diseño de las políticas para lograr sus objetivos estratégicos, operativos y, en consecuencia, sus metas; lo cual exige conocer la versatilidad de este sector para que la política pública responda a las necesidades de las comunidades que participan, directa o indirectamente, en la servucción ${ }^{1}$ del producto turístico (M agaña, 2005). López Palomeque señala que "la especial dificultad de delimitar las actividades estrictamente turísticas, eleva la complejidad en el momento de afrontar el diseño de una política turística" (2004: 14).

La falta de conocimiento que se llega a tener en el diseño de la política pública turística provoca que los resultados no produzcan beneficios, pues de acuerdo con López Palomeque, "Las restricciones internas que reducen la viabilidad y éxito en ese proceso de formulación pueden ser, entre otras, regulando la calidad de los establecimientos de oferta, el uso de los recursos turísticos por los residentes, la capacitación de los recursos humanos, la disponibilidad de suelo y el volumen de inversiones (2004: 17). Estas consideraciones muestran los resultados no competitivos en los mercados, donde se involucra directamente la satisfacción del cliente (interno o externo) del producto turístico.

Es necesario agregar el hecho de que la naturaleza de los sitios donde se encuentren los recursos turísticos tiene sus propias características; por tanto, la política necesita incluir cada uno de estos elementos para que el beneficio sea efectivo. En consecuencia: "Los objetivos de la política turística son numerosos y divergentes para cada zona, región o país, además de que van a depender de los productos turísticos existentes y de las motivaciones y directrices de las autoridades responsables de institucionalizar la política turística" (M onfort, 2000: 15).

La intervención de la administración pública en este sector en el último medio siglo se formalizó en lo que se denomina política turística, la cual se ha ido adaptando a las condiciones y a las

${ }^{1}$ El término se refiere a un concepto más adecuado para definir la producción de un servicio, como el conjunto de pasos que dan origen al proceso para formar dicho producto intangible. Lo propuso Larrea (1991) y la autora lo retomó como una posibilidad para medir el proceso y poder aplicar el control total de calidad en el mismo, utilizando las herramientas de calidad, tanto las siete herramientas básicas y las siete herramientas cualitativas de Karl Albrecht (1994b). 
diversas necesidades del sector. Esta intervención se justifica en la participación y regulación de la naturaleza de los recursos, productos y espacios, así como en el significado que tiene el lugar o el espacio como producto turístico. López Palomeque concibe esta relación como la "que permite conseguir la calidad y la competitividad de los destinos-productos turísticos" (2004: 39).

Asimismo cabe mencionar un ejemplo de la relación positiva entre política y recurso turístico: es el caso de Cataluña, donde la participación de la administración pública en el sistema turístico, aunque por motivos distintos a la intervención tradicional, durante décadas ha permitido el desarrollo turístico de esa región. También queda claro cómo, histórica y espacialmente, el turismo ha recibido un fuerte apoyo: "en el proceso de conformación del model o turístico catalán, la administración pública ha desempeñado un papel clave, ha constituido uno de los factores de desarrollo del turismo en Cataluña" (López Palomeque, 2004: 36).

Así, el gobierno es responsable de la política pública y su administración, pero es necesario resaltar su naturaleza sociopolítica en el contexto de la sociedad en general, y específicamente en los beneficios o no del sector turístico como clientes finales. La política pública es el instrumento del gobierno para satisfacer al turismo en sus necesidades y expectativas, por tanto, es fundamental que tales políticas se diseñen apegadas a una metodología. Se debe considerar, entonces, que la política pública es más que técnica, requiere alcanzar resultados y que los actores del sector turístico, como empresas y organizaciones, incluida la academia, participen de manera coordinada y con base en acuerdos con el gobierno. De esta manera es posible generar la política pública turística necesaria para ser y hacer competitivo como producto al destino turístico México.

\subsection{La evolución de la política turística en M éxico: una perspectiva desde el modelo de calidad total}

Con base en el análisis de las políticas turísticas elaborado por Alfonso Jiménez (1993), desde el enfoque del modelo de calidad total, se realizó un mapeo de las acciones de la política turística a partir de 1949 para identificar qué acciones han sido congruentes con la perspectiva integral de este modelo. No hay duda del impulso y crecimiento en el sector turismo, pero intentamos explicar por qué en la actualidad no es competitivo; en contraste, el modelo de calidad total sí ha comprobado su efectividad. 
En esta sección nos referimos, de manera general, al proceso que $M$ éxico ha seguido para que se reconozca al turismo como una actividad económicamente importante. De acuerdo con la información del Centro de Estudios Sociales y de O pinión Pública (CESOP), del Congreso de la Unión (2006), en el desarrollo del turismo moderno mexicano en relación con el internacional se pueden identificar tres periodos: el primero, después de 1945, al final de la segunda Guerra M undial hasta la introducción de la aviación comercial, en 1958; el segundo comprende de 1959 a 1970, momento crítico para el turismo mexicano, pues comienza la planeación de los centros turísticos; y el tercero a partir de 1973, cuando comienza la operación de estos centros y se observan los primeros resultados.

Considerando la condiciones que prevalecían al final de la segunda Guerra M undial, M éxico tuvo una disminución en sus exportaciones, principalmente a su mercado natural: Estados Unidos. Fue entonces que el gobierno tomó la decisión de desarrollar al país por medio de la industrialización; pero no se tenían capitales ni las inversiones para impulsarla. En este momento crítico, M iguel Alemán Valdés (1946-1952) se convirtió en el primer presidente de M éxico que identificó al turismo como un fenómeno económico; vio que por medio de éste se podían obtener las divisas que permitirían financiar la industria de la transformación. Durante su campaña en 1946 presentó la “D eclaración Turística" o "Carta Turística", en la que resaltaba que el turismo nacional y extranjero serían útiles para desarrollar muchas zonas del país (Jiménez, 1993).

En este primer momento se identificó al turismo como simple recurso económico; pues era claro que el interés del gobierno era manejar al turismo sólo como una fuente de ingresos para desarrollar la industria de la transformación mexicana. D ebido a que no se elaboraron estudios al respecto, en esa época no se concebía establecer un proyecto integral para el país, no hubo una planeación para la actividad económica en su conjunto y se desconocía el potencial del turismo para M éxico. Por tanto, no se forma una visión en el tiempo y en el espacio de lo que M éxico quería ser turísticamente en el futuro, el cual hoy es su presente, pero limitado.

Para concluir con el periodo de M iguel Alemán, durante su gobierno se crearon los primeros polos turísticos, hoy conocidos como destinos tradicionales: Acapulco, M anzanillo, M azatlán, Puerto Vallarta, Cabo San Lucas, Cozumel, Isla M ujeres, Vera- 
cruz, M érida, Guadalajara y la ciudad de M éxico. Se puede decir, entonces, que es en ese sexenio que M éxico se ocupa del turismo y en 1949 se promulga la primera Ley Federal de Turismo (CESOP, 2006).

Durante la administración de Adolfo Ruiz Cortines (19521958), también desde una perspectiva económica, se fomenta la actividad turística dirigida sobre todo hacia el interior del país. Se creó el sistema de carreteras nacionales; en 1958 se impulsó el desarrollo hotelero: en 1946 se contaba con 4,200 habitaciones, que para 1958 había aumentado a 82,438 en 2,998 hoteles (Jiménez, 1993). De acuerdo con los anterior, es posible afirmar que en estos dos sexenios se fortaleció la infraestructura turística: desde carreteras hasta centrales de autobuses y comenzaron a operar algunas líneas aéreas internacionales, con lo que también se establecieron los cimientos de la industria turística institucional.

Como se puede ver, no se produjo un concepto de administración integral para manejar de forma planeada la actividad y los productos turísticos (por ejemplo, destinos turísticos), es decir, se proyecta a M éxico como destino turístico sin considerar la necesidad imperiosa de capacitar integralmente a un sector que estaba naciendo; no se identificaron efectos, beneficios, tendencias, entre otros, porque no se estudió al turismo en su esencia, identificando lo que es y representa.

Los presidentes Adolfo López M ateos (1958-1964) y Gustavo Díaz Ordaz (1964-1970) fomentaron la identidad nacional incorporando a los atractivos turísticos la historia y cultura de M éxico. Hubo un decidido respaldo a la inversión extranjera representada, principalmente, por cadenas hoteleras internacionales, lo que generó un aumento de habitaciones y comenzó la promoción de M éxico en diferentes medios en el ámbito internacional. En cuanto a la promoción, pareciera que es la parte más importante del turismo; por supuesto ésta es necesaria para vender un producto en el mercado, pero no se toma en cuenta que es indispensable sustentar lo que se ofrece; hasta la fecha, se cree que turismo es casi un sinónimo de promoción. Y es justamente en ese rubro donde se ha desperdiciado gran parte de recursos económicos, pues se olvida el proceso de servucción del producto turístico (el qué), así como el servicio o entrega (el cómo). Esto es parte de la filosofía del servicio propuesta por la autora (M agaña, 2004: 4, 23, 44) con el concepto de calidad total; es decir, primero estudiar, saber escuchar lo que el cliente interno y externo necesita, espera y desea, para tener los insu- 
mos que garantizarán su satisfacción y lealtad al producto turístico M éxico (Ibid: 68).

En 1962 se crea el primer Plan N acional de Desarrollo Turístico; a pesar de que ya se considera un plan formal, no se desarrolla desde el concepto de planeación estratégica en el sentido estricto de esta filosofía; otra vez se pierde la oportunidad de establecer un proyecto de país e integrar al turismo como una fortaleza económica. Se consideró, nuevamente, fortalecer la infraestructura turística y sus aspectos periféricos -que desde luego es necesario contemplarlos-, pero se olvidó otro aspecto muy importante para proyectarse fuertemente hacia la competitividad en los mercados turísticos, el capital humano: empresarios y directivos, la alta gerencia, como lo Ilama Peter D rucker (M agaña, 2004: 78).

El presidente Luis Echeverría Álvarez (1970-1976) incentivó la actividad turística mediante la aplicación de políticas que buscaban aumentar la afluencia de visitantes a nuestro país. Se impulsó el Caribe mexicano, sobre todo Cancún y Quintana Roo, sitios que recibieron un ímpetu en el desarrollo planeado, lo que constituyó una ventaja en cuanto al aprovechamiento de los recursos y la derrama de beneficios para la región y fortaleció al sector en general. En este periodo se fomentaron las coinversiones para afianzar la infraestructura en hotelería; en especial aumentó la oferta de cuartos con categoría turística. El hecho de manejar los hoteles mediante el concepto de categorías permitió a M éxico mejorar su oferta de hospedaje a niveles competitivos internacionalmente.

Durante el gobierno del presidente José López Portillo (19761982) se identificó la importancia del turismo como fuente generadora de divisas. Se insistió en mejorar la infraestructura, sobre todo el transporte y las comunicaciones, así como abrir posibilidades a la inversión privada nacional y extranjera. Se brindaron apoyos fiscales y se otorgaron créditos para sostener la inversión en este sector. Se inició la clasificación turística de los hoteles, lo que permitió organizar la promoción y comercialización del hospedaje en los principales destinos turísticos nacionales. Esta clasificación se hizo en las siguientes categorías: de una a cinco estrellas y gran turismo. Se implantaron tarifas acordes y se promovió el turismo para los trabajadores y sus familias, creándose el Fideicomiso Obrero para el Turismo (CESOP, 2006). Este tipo de turismo buscó fortalecer la unión familiar, con lo que comenzó el Ilamado turismo social, el cual contempla instalaciones de 
categoría media para responder a otra área importante del sector turístico, con instalaciones que satisficieran sus muy particulares necesidades. Para apoyar el financiamiento de la actividad se fundó el Banco Nacional de Turismo, el cual otorgó recursos que reforzaron la mano de obra y la operación de los negocios (Jiménez, 1993). Sin embargo, este enfoque pone de manifiesto que sólo se consideró una parte del sistema de trabajo con necesidad de capacitación: el nivel operativo de la empresa, dejando a un lado la dirección de la misma.

Con el presidente $\mathrm{M}$ iguel de la M adrid H urtado (1982-1988) comenzó la apertura de la economía del país a otros mercados, lo que benefició el establecimiento de la política turística que contemplaba una estrategia general. Ésta consistió en usar de manera eficiente e intensiva la capacidad instalada e implantar una política de precios competitiva en el ámbito internacional, con el fin de estar a la par con los destinos turísticos del mundo.

Se promovió el tianguis turístico con el Programa Nacional de Turismo 1984-1988, como un evento internacional para que M éxico ofrezca, comercialice, promueva y difunda sus productos a operadores y periodistas nacionales y extranjeros especializados, sobre todo de Estados Unidos y Canadá, mercados naturales de M éxico, pero también de algunos países de Europa. Por otro lado, el Banco N acional de Turismo no pudo atender a sus clientes y fue liquidado. En cuanto a la información especializada en turismo, se consolidó un sistema que mejoraría su manejo y utilización, al tiempo que apoyaría en la contabilidad del sector; no obstante, para esas fechas no había arrojado resultados claros (Jiménez, 1993). Sin embargo, hasta entonces no existía una política para formar a los empresarios y trabajadores de este sector en un contexto de visión estratégica, tampoco había capacitación en el concepto del modelo de calidad total, que en esos años ya daba resultados en la economía japonesa y que le valió, de acuerdo con el Reporte G lobal de Competitividad 2007-2008, que ahora sea una de las primeras diez economías del mundo, a menos de tres puntos del primer sitio (Porter et al., 2007).

En la administración de Carlos Salinas de Gortari (1988-1994) se fortaleció la promoción del turismo en Estados Unidos y Europa. En las políticas turísticas se puso de manifiesto este interés, en el que nuevamente se apoya una ampliación de las inversiones en infraestructura y se impulsaron varios megaproyectos, con el objeto de ampliar la oferta turística y generar empleos. 
También se atendió la capacitación de los trabajadores, sin embargo se olvidó formar la cultura empresarial del sector.

Con el presidente Ernesto Z edillo Ponce de León (1994-2000), el Programa de Desarrollo del Sector Turismo 1995-2000 se orientó a fortalecer la competitividad y sustentabilidad de los productos turísticos mexicanos, los que coadyuvarían en la creación de empleos, la captación de divisas y el fomento al desarrollo regional. Esto demandó realizar investigaciones que dieran las pautas para diseñar estrategias que permitieran incursionar y satisfacer a nuevos mercados.

En el gobierno de Vicente Fox Quesada (2000-2006), con el PNT 2001-2006 se confirma que la actividad turística se puede considerar uno de los factores decisivos para aumentar las oportunidades, mejorar la distribución del ingreso y utilizar -mediante un concepto de sustentabilidad- Ios recursos naturales y culturales. Además, se puso énfasis en una nueva política turística cuyo propósito es revertir las inercias que han limitado el potencial de este sector, la cual sería un agente de cambio y transformación, una fuente verdadera de riqueza económica y desarrollo social para M éxico. Esta administración se comprometió a hacer del turismo una prioridad nacional y convertirlo en país líder en esta actividad.

Por primera vez, el PNT presenta la planeación estratégica del turismo de M éxico con una visión a 25 años:

En el año 2025 M éxico será un país líder en la actividad turística, ya que habrá diversificado sus mercados, productos y destinos y sus empresas serán más competitivas en los ámbitos nacional e internacional. El turismo será reconocido como pieza clave en el desarrollo económico y su crecimiento se habrá dado con respeto a los entornos naturales, culturales y sociales, contribuyendo al fortalecimiento de la identidad nacional (p. 4).

EI PNT también establece la misión de la actividad turística: "Conducir el desarrollo turístico nacional, mediante las actividades de planeación, impulso al desarrollo de la oferta, apoyo a la operación de los servicios turísticos y la promoción, articulando las acciones de diferentes instancias y niveles de gobierno" (p. 40).

Con Felipe Calderón H inojosa (2006-2012) comenzó el PND, con el lema "Visión M éxico 2030". Atendiendo a la Ley de Planeación, se destaca que el PST surge de un proceso de planeación participativa, de estudios puntuales en competitividad, desarrollo y evaluación de política pública. Específicamente, con el Eje 
de "Acción 2" del PND se busca lograr una economía nacional competitiva, productiva, eficiente y generadora de empleos. En el "Gran objetivo nacional para el sector turístico nacional" se menciona que es necesario "H acer de M éxico un país líder en la actividad turística a través de la diversificación de sus mercados, productos y destinos, así como el fomento a la competitividad de las empresas del sector de forma que brinden un servicio de calidad internacional" (Sectur, 2007: 16).

La política pública es el instrumento mediante el cual el gobierno define su plan de trabajo, las acciones necesarias para obtener resultados y cómo traducir los beneficios cualitativos y cuantitativos a favor de la comunidad receptora. En IOS PNT, y ahora en el PST, aún no se contempla de manera concreta un proyecto de capacitación y entrenamiento para que los empresarios del sector adquieran competencias: en su pensamiento, actitud hacia conceptos, filosofías y formas de dirección de negocios que trabajen en pro de la sustentabilidad y la competitividad; todo ello para ubicarse en los mercados turísticos internacionales.

Pareciera que el gobierno mexicano sólo ha concebido al turismo como una actividad económica y no los ha estudiado como un fenómeno social, cuya consecuencia es la ausencia de una concepción integral de éste, generando así limitaciones en su valor, efectos y usos sociales en la productividad y competitividad del sector.

En el sentido en que se ha venido analizando el contenido de la propuesta de loS PNT (hoy PST), cuando se habla de oferta en el tema de condiciones, pareciera que la limitan sólo a los recursos que forman el atractivo turístico y no toman en cuenta las habilidades y actitudes del capital humano en general, que participa en los diferentes contextos del campo del turismo como negocio, y que sin embargo es quien toma las decisiones internas y externas de su organización.

No obstante, el gobierno de M éxico todavía no ha dimensionado claramente al turismo como un concepto integral para convertirlo en un pilar de la economía nacional. Los sectores público y privado del país deben ser un binomio que genere los elementos vitales para ser y hacer un ejercicio competitivo en la dirección y acción del turismo en la política nacional. La expresión de la política turística -a lo largo de los diferentes periodos gubernamentales- deja entrever, de manera concisa, que en el destino turístico M éxico no se ha fortalecido una cultura empresarial capaz de poner en juego una diversidad de acciones que le permitan ser competitivo en los actuales mercados turísticos mundiales en el contexto de la hipercompetitividad. 
Acerca del concepto de producto y destino, compartimos lo que menciona López Palomeque:

La complejidad del producto turístico es un hecho derivado del propio fenómeno de su singular significado como actividad económica. En los últimos años se utiliza cada vez más el concepto producto turístico como representativo de una realidad compleja y sustitutoria de conceptos anteriores menos agregados, menos complejos, como por ejemplo el de alojamiento-producto o el de restauración-producto. Un producto turístico es, pues, una combinación de prestaciones y elementos tangibles e intangibles que ofrecen unos beneficios al cliente como respuesta a determinadas expectativas y motivaciones (2004: 40).

Ésta es la concepción adecuada para el producto destino turístico M éxico, así como lo que manifiestan Albrecht (1994a), Juran (1990) y Picazo y M artínez (1991) cuando consideran al producto como un conjunto de beneficios integrales, de proporciones y beneficios cuantitativos y cualitativos (M agaña, 2005) y no solamente como hasta ahora el gobierno considera al turismo: como generador de recursos económicos para el país.

\subsection{El sector privado empresarial y la alta dirección en el turismo}

Es evidente que el sector privado es la mano operativa del turismo. En ello radica su gran importancia para el análisis que se hace en este artículo. El sector privado es el motor de la economía turística, es el principal interesado en impulsar la actividad. Recordemos que el turismo es el tercer generador de divisas del país; de acuerdo con la Cuenta Satélite del Turismo de M éxico de 2004 , aporta $7.8 \%$ del producto interno bruto (PIB) del total nacional. Aquí también participan las micro, pequeñas y medianas empresas ( $M$ ipymes) mexicanas, las grandes empresas y las cadenas hoteleras instaladas en M éxico. Elliot señala que "es la 'industria', particularmente del sector privado, el que juega un papel preponderante en el desarrollo del turismo y el que provee la mayor parte de la inversión, los hoteles y resorts, los parques temáticos, agencias de viajes, guías de turistas y la mayor parte de la transportación" (1997: 178). No cabe duda, entonces, de su importancia en la actividad turística, del alcance de sus acciones y, por ende, de su filosofía.

Por su parte, la participación del gobierno en la administración del sector privado no debe perder de vista su responsabilidad en los aspectos cualitativos (no económicos) del turismo 
(Bramwell y Sharman, 1999) para impulsar acciones que no sólo estén basadas o resalten el aspecto económico, pues estaría propiciando un desequilibrio y resultados poco importantes a largo plazo. Elliot también apoya la idea de que el gobierno debe participar mediante políticas que controlen circunstancias relacionadas con el turismo: la política, la formulación estratégica, las iniciativas de desarrollo y la mercadotecnia, la coordinación, los estándares de calidad, los servicios de información turística, la investigación, el desarrollo perspicaz, la educación, el entrenamiento y el liderazgo (1997: 179-180).

La alta dirección de la empresa es quien tiene la responsabilidad de las acciones de organización; por lo que es indispensable definir este concepto y su papel en el modelo de calidad total. En el lenguaje de la administración para la calidad, la alta dirección también se conoce como alta administración o alta gerencia.

La alta gerencia la forman los directivos de una empresa, que son los responsables de tomar decisiones. Una organización se crea y diseña para alcanzar un fin, el cual decide el director general y/o el equipo de alta dirección. La estructura y diseño es el resultado final de este propósito. La responsabilidad principal de la alta dirección es determinar las metas, su estrategia y el diseño que permita que la empresa se adapte a un ambiente en constante cambio. Por su parte, los gerentes medios hacen lo mismo para los distintos departamentos con base en las líneas de acción dadas por la alta dirección (D aft, 1998: 46).

D efinitivamente, los líderes especializados en planificar decisiones importantes ocupan más tiempo en crear un valor de estrategia que en actividades operacionales. En general se sugiere que estos líderes se concentren en crear, innovar, mejorar y estandarizar la estrategia competitiva, así como los sistemas y las políticas corporativas. En contraste, los operadores se ocupan de lo rutinario, el mantenimiento, la ejecución de tecnología de procesos y de la operación de métodos y tareas (Bounds et al., 1994: 155).

Peter Drucker (1999) menciona que la principal tarea de la alta dirección es pensar con base en la misión de negocio; lo que significa contestar las interrogantes: ¿cuál es nuestro negocio? y ¿cuál debería ser? Esto se relaciona con la determinación de objetivos, el desarrollo de estrategias y la toma de decisiones que afectarán los resultados. Lo anterior sólo lo puede realizar un organismo de la empresa que vea el negocio de manera integral y que además sea capaz de balancear objetivos, así como las nece- 
sidades de hoy contra las de mañana, y que también sepa asignar recursos humanos y económicos para lograr resultados. Drucker agrega que la dirección debe tener el poder para hacer su trabajo, cualquiera que sea la organización - por ejemplo, la Diócesis católica, la universidad, el hospital, el sindicato y los negocios o empresas-, esto es igual a tener legitimidad (1999: 180). Drucker también señala que la dirección en turno es el órgano de la institución. En cuanto a la pregunta ¿qué es la dirección?, primero se debe definir ésta de acuerdo con sus tareas, igualmente importantes pero diferentes en esencia: "Ia dirección tiene que hacer capaz a la institución en su responsabilidad para su función y su contribución" (2001: 14).

Las organizaciones sociales turísticas también juegan un papel importante en el desarrollo nacional y en los mercados internacionales. Por medio de ellas se crean relaciones comerciales, de información sobre tendencias de mercado, de promoción, difusión, de amistad, entre otros. Asimismo, las asociaciones o cámaras desempeñan funciones primordiales entre los miembros de un sector: reúnen información, promueven la comunicación con miembrosy gobiernos, ayudan a formular una imagen colectiva de sus agremiados, así como de la política de la organización. "La administración pública trata de mantenerse en contacto y consultar con este tipo de asociaciones, esto hace que las asociaciones se encuentren en posición de poder" (Elliot, 1997: 188).

Entendemos que el turismo como actividad económica requiere generar resultados que se traduzcan en beneficios cualitativos y cuantitativos para el país y, por ende, para sus comunidades en forma directa, sin dejar de considerar sus efectos y usos sociales indirectos. De acuerdo con los resultados productivos, económicos y sociales que el modelo de calidad total ha mostrado, se plantea que el turismo se administre desde el concepto modelo de servir con calidad total; esto es, mediante un enfoque que incluya aspectos cuantitativos y cualitativos desde la concepción misma de la calidad, donde se contemple el control total de calidad para la servucción del producto o servicio base (el qué) y la entrega o servicio (el cómo). Aun con su complejidad, esto permitirá una gestión más efectiva del turismo (M agaña, 2004, 2005). Por ello se aborda el papel de la alta dirección, en sentido estricto del manejo de un modelo de esta naturaleza.

Para especificar la importancia de la dirección es necesario tomar en cuenta el enfoque del modelo de calidad total, así como a los especialistas para conocer su opinión en cuanto a la función 
que desempeña la alta dirección. Durante el desarrollo de sus teorías, el doctor Deming identificó que es precisamente la alta dirección la responsable de comprometerse con la calidad total, pues "sin la presión de la gerencia para obtener calidad, nada se lograría" (Walton, 1992: 10).

Para Juran y Gryna, "de todos los ingredientes para lograr con éxito la superioridad en la calidad, sobresale uno: el liderazgo activo de la alta administración. Se supone que existe el compromiso con la calidad, pero no es suficiente" (1995: 142). De acuerdo con estos autores, se pueden identificar algunas tareas que debe asumir la alta administración: a) establecer y servir al consejo de calidad, b) crear políticas de calidad, c) elaborar las metas de calidad, e) proporcionar los recursos, f) dar capacitación para resolver problemas, g) participar en los equipos para mejorar la calidad de la alta administración, h) estimular la eficiencia, e i) proporcionar recompensas y reconocimientos

La dirección para la calidad total (total quality management, TQM ) "es un tema actual en los negocios y círculos académicos. Los gerentes de negocios están tratando fervientemente de pensar cómo hacer [la TQM ]" (Bounds et al., 1994: 2).

Desde esta perspectiva se identifica la alta dirección de las empresas del sector privado, para que sean las que adopten y adapten las políticas turísticas que marca el gobierno. Asimismo, que se incluya en tales políticas la necesidad de ofrecer un panorama más amplio y la preocupación por capacitar a esta alta dirección en el sentido de un modelo de servir con calidad total para que se implante en toda la actividad turística. Actualmente, la alta dirección de las M ipymes no es competitiva en el sector turismo debido a un sinfín de características, como su concepción, nuestra cultura tradicional, e incluso a nuestra falta de cultura de calidad.

\section{La competitividad mundial y el modelo de servir con calidad total}

En este artículo se pretende sustentar claramente los límites y los alcances del término competitividad con el objetivo de comprender las interrelaciones entre calidad, acciones gubernamentales, alta dirección del sector privado y turismo.

La competitividad es un concepto que se encuentra muy cercano al hecho de que el costo final del producto coincida con la voluntad de pago del potencial cliente externo. Resulta obvio que 
no hay problema de competitividad cuando no existen competidores, de ahí que la diferenciación constituya una estrategia clave para conseguir la competitividad (García y Serrano, 2003: 424). La empresa que tenga las habilidades suficientes y sea capaz de gestionarlas de manera adecuada para colocar sus productos 0 servicios en el mercado es una empresa competitiva. Con frecuencia se habla de ser competitivos y esta expresión se aplica sin distinguir si se trata de competencia entre productos, empresas, sectores, países o regiones (Ibid.: 425). La competencia se encuentra en todos lados y en todos sentidos: entre empresas, en los ámbitos local, regional, nacional o internacional. Es necesario estar preparado y ser competitivo para ser parte del mercado.

Si analizamos lo que señala Porter en relación con los diversos impedimentos para la competencia global, vemos que algunos son económicos, otros acerca de la tarea administrativa, "una tercera categoría se relaciona con las restricciones puramente gubernamentales o institucionales que no reflejan las circunstancias económicas" (1996: 294); por tanto, ya es tiempo de que el gobierno mexicano considere un diseño de política pública apoyado en estudios sobre turismo -como fenómeno social y como actividad turística-, de manera que éste sea más efectivo en su plan de acción y su implementación.

La hipercompetencia "es un término usado con frecuencia para captar la realidad del panorama de la competencia en el siglo xxı, es el resultado de la dinámica de las maniobras estratégicas de combatientes e innovadores. Es una condición de la rápida escalada competitiva basada en el posicionamiento en la calidad y el precio para crear conocimientos técnicos nuevos y establecer la ventaja del pionero y de la competencia por proteger o por invadir mercados establecidos, sean geográficos o de productos" (H itt et al., 2004: 11). Éste es un concepto del cual el turismo mexicano no se puede abstraer, una realidad presente en donde no se está preparado para participar.

En el apartado "La competitividad del producto turístico mexicano" del PNT 2001-2006 se habla de que para M éxico es prioridad la actividad turística, ofrece datos del crecimiento sostenido de este sector y se asegura que "no obstante, la industria turística nacional muestra al gunos signos de pérdida de competitividad, que es necesario considerar para su futuro desarrollo" (Sectur, 2001).

Entre estos signos de pérdida de competitividad se encuentran diversos indicadores: Ias posiciones internacionales, los ingresos por visitante, la cantidad de turistas extranjeros, la esta- 
día promedio y la concentración de flujos en algunos destinos. Asimismo, se percibe de manera desventajosa en rubros como entrega de producto y condiciones de higiene. Las consideraciones anteriores se deben, al menos en parte, a que los ejes fundamentales del modelo de desarrollo se basan, principalmente, en la promoción de grandes urbanizaciones de playa, inversiones hoteleras y obras de infraestructura política. Esto ya no será viable en el futuro inmediato, puesto que las prioridades de la inversión pública necesitan medirse en índices cualitativos como: educación en todos los niveles, seguridad social, combate a la pobreza, seguridad pública, bienestar, salud pública, principios y valores de la nación, valores personales de los mexicanos, satisfacción individual, entre otros. Junto con esto, el modelo actual no reconoce de manera integral las amplias posibilidades que presenta el turismo para generar riqueza cultural y social, distribuir mejor el ingreso, así como aprovechar los recursos naturales y culturales del país.

Como ya se mencionó, no hacer una planeación estratégica (PE) para el país y una planeación operativa (PO) para aplicar la PE, ha dado como resultado el "bajo perfil estratégico que se ha otorgado al turismo como detonador del desarrollo del país, ha contribuido en gran medida a la pérdida de competitividad en el mercado mundial" (Sectur, 2001: 51). Un primer paso en estos modelos de administrar desde la calidad es reconocer qué se tiene y qué falta para poder rediseñar y avanzar.

Por su parte, para hacer operativas las acciones estratégicas del sector, en el PST 2007 se propone seguir índices de competitividad mundiales. Estos índices son, sobre todo, los que marca el Reporte Global de Competitividad del Foro Económico M undial y los de competitividad turística de la O rganización M undial del Turismo (Sectur, 2007), los cuales se abordaron en el apartado del análisis de la política turística respectiva a este periodo.

Para lograr la competitividad de M éxico como destino turístico es necesario atender ambos aspectos: que el gobierno comprenda su posición y actúe incluyendo en su política pública conceptos más amplios, como la integración del estudio y la capacitación de la alta dirección para el manejo de los negocios. El modelo de servir con calidad total es el que debe proponer el gobierno, pues es el que conviene que adopte el sector privado para que logremos competitividad en el turismo.

De lo analizado hasta aquí se puede observar que en sus planes y programas los diferentes gobiernos han ido definiendo un 
proyecto para desarrollar a M éxico en el aspecto turístico. Sin embargo, sólo lo ha hecho enfocándose en los recursos de infraestructura y estructura; esto dio como resultado el incremento en los visitantes a nuestro país, pero dejó el capital humano del sector fuera de una política que contemplara la capacitación y el adiestramiento de un sector turístico privado que fuera consciente de su papel y posición para la mejora, crecimiento, presencia oportuna y permanente en los diferentes mercados turísticos internacionales.

Consideramos que se deja fuera al elemento humano porque el gobierno ha demostrado su falta de conocimiento integral de lo que es el turismo. Al empleado sólo se incluye en capacitación para aspectos operativos en el trabajo y no para construir una estrategia basada en quienes hacen el servicio base o producto, así como la entrega del servicio turístico al visitante. Por tanto, es urgente promover una política turística que conduzca a crear una cultura de servir con calidad total en la oferta turística, una cultura empresarial competitiva, para así garantizar la satisfacción del cliente interno y externo en forma integral; para que sean ellos los servuctores de los destinos turísticos.

Las aportaciones de Baker y Fesenmaier en su estudio del servicio apuntan: "El reconocimiento del potencial de la calidad del servicio, para establecer una ventaja competitiva para las organizaciones de servicio, surgió en la década de los ochenta" (1997: 15). D efinitivamente, de acuerdo con esta afirmación, la calidad del servicio es una ventaja competitiva en el mercado para quienes logran establecerla, y su cliente externo la identifica y disfruta. En virtud de que el sector turístico corresponde eminentemente al área de servicios, estará obligado a servuccir y entregar al cliente externo calidad en los productos tangibles e intangibles que ofrece, independientemente de la categoría y tamaño del establecimiento. Esa servucción y entrega enfocados hacia un concepto integrador de valor de cliente se vuelve necesario. Picazo y M artínez coinciden en que "Para lograr ventajas competitivas, la formulación de estrategias debe centrarse prioritariamente en el cliente" (1991: 35). La estrategia de servicio consiste en una atención integral al cliente externo: antes, durante y posterior a la venta.

Podemos afirmar de manera categórica que el crecimiento de los negocios de servicios en $M$ éxico y el papel que desempeñan en la economía mundial, reafirma la necesidad imperiosa que tiene la dirección de las empresas de actualizar su manejo. Se 
debe facilitar y garantizar la satisfacción del cliente externo, así como conocer las tendencias del mercado en el que compite. La dirección de las empresas de servicios debe estar consciente de toda actividad económica y comercial; igualmente, debe tener su enfoque, su propio lenguaje, su propia filosofía y su propuesta. Entender, utilizar y aplicar estos términos, en su conjunto, permite una conducción más adecuada del negocio y su ubicación en el mercado correcto.

Se observa que la calidad del servicio es una ventaja competitiva en el mercado. También es necesario considerar que en la actualidad la estrategia de servicio requiere una atención integral hacia el cliente externo, la cual asegure su satisfacción antes, durante y después de realizar la venta. Lograr este proceso garantizará a la empresa obtener la lealtad del cliente.

El turismo en M éxico ocupa el tercer lugar en importancia como captador de divisas. Los beneficios cuantitativos y cualitativos tienen efectos directos e indirectos en las economías locales. A partir de la discusión teórica efectuada, es posible afirmar que establecer y asegurar la calidad por medio de la estandarización de los productos y servicios turísticos es una estrategia necesaria para mantener la preferencia del cliente-turista.

En el PND 2001-2006, en el PNT 2001-2006 y en el PST 20072012 se hace énfasis en la productividad empresarial. En este sentido, el reto está en el nivel directivo de las empresas turísticas del país, en las diferentes clases y categorías. Lo importante es que se decidan y participen en realizar una jornada nacional; que acepten, aprendan, se involucren, que hagan con calidad sus productos y servicios turísticos para poder participar en la competencia mundial. En efecto, para tener éxito en la actividad turística es necesaria la buena relación entre los sectores que intervienen: el oficial (público gubernamental), el productivo (la iniciativa privada) y el social (organizaciones no gubernamentales, asociaciones, cámaras, entre otras), así como en su desarrollo y con el apoyo de otras actividades económicas. Estas características se han ignorado, lo que impide un desarrollo armonioso del turismo en nuestro país.

Sin embargo, en este trabajo se reconoce que aún no contamos con un sistema de organización y coordinación que se adapte a las necesidades del país y los mercados actuales, por lo que proponemos investigar y elaborar formas diferentes de dirección en los negocios turísticos, teniendo como base la idea de que el cliente-turista busca no sólo el atractivo natural o cultural del 
país, sino llegar a un sitio que tiene como oferta el valor de cliente en su producto y servicio turístico nacional, independientemente de su elección del atractivo y categoría. Es mediante la decisión política que la actividad turística puede lograr un cambio integral, donde los involucrados en sus diferentes instancias (pública, privada y social) estén dispuestos a hacer para que se dé el cambio. De ahí que no sólo es necesaria más infraestructura y estructura turísticas, sino también sistemas, procedimientos eficientes y elementos humanos capacitados, comprometidos y decididos, desde el ámbito de la dirección para servuccir el servicio-base turístico (producto) y la entrega de calidad total, que transformen a M éxico en un destino turístico de clase mundial.

$\mathrm{N}$ o es sólo la capacitación del elemento humano operativo en forma aislada -como se ha hecho durante varios sexenios- 10 importante, sino una capacitación que garantice la calidad en el producto y servicio turísticos. Así que no es exclusiva del ámbito operativo la responsabilidad de la satisfacción total del cliente externo; es en la dirección de la estructura administrativa donde se genera lo que es realmente la empresa en el momento de la verdad, cuando se tiene enfrente al cliente externo; es decir, la responsabilidad de dar o no dar calidad recae en la dirección de la empresa.

El problema de M éxico es que en el pasado la planeación del desarrollo nacional no se consideró en forma integral y estratégica. A finales del siglo xx, los mercados abiertos a la libre competencia relegaban los productos que no estaban preparados para ofrecer calidad y no eran oportunos. Así, se puede decir que en el siglo xxı la competencia es más agresiva y las exigencias de los mercados son más marcadas, lo que llevó a M éxico a quedar en desventaja como receptor y como destino turístico internacional, precisamente porque no tiene un modelo de servir con calidad total, lo que no le permite anticiparse y ser oportuno para sus clientes potenciales y reales. Como se evidencia en el Programa N acional de Turismo 2001-2006 (Sectur, 2001), M éxico es un producto turístico no competitivo, pues se encuentra atrasado frente a los destinos turísticos competitivos mundiales. La mayor parte de la cultura empresarial turística del país no es profesional; en muchas ocasiones su relación con el cliente externo es de ganar/perder. Este programa muestra algunos signos de pérdida de competitividad.

La propuesta en el PNT 2001-2006 de hacer evaluaciones estratégicas puede garantizar que se corrija el rumbo en forma 
permanente, soportando un desarrollo turístico de acuerdo con la realidad que se vaya presentando, así como a seguir el camino que lo lleve a un futuro con mayor certidumbre. EI PST 20072012 propone un ejercicio de planeación operativa desde la planeación estratégica, el cual, sin duda, será exitoso. Si se aplica desde un sustento teórico, el avance será claro y medible.

\section{Conclusiones}

H asta el momento, las políticas establecidas para desarrollar la oferta, en sus renglones de infraestructura y estructura, fueron importantes para el desarrollo turístico nacional y su promoción en el exterior. N o obstante, se ha considerado muy poco la sistematización de los procesos y las tareas. Se dio menos importancia a filosofías como la del servicio de calidad total, donde se contempla al capital humano como parte central.

En la superestructura se encuentra la cultura empresarial que aún necesita conocer y aprender formas de ser y hacer desde la empresa turística para satisfacer al cliente interno y externo. También las autoridades -en los tres niveles de gobierno- necesitan estudiar lo que es y representa el turismo, para que sean capaces de responder a las expectativas facilitando -por medio de la política pública- la dirección y la acción de la actividad, para que tenga efectos en beneficio del país.

A lo largo de este análisis se establece claramente el papel importante y definitivo que tiene la dirección de los negocios para satisfacer al cliente interno y externo. Dado que es urgente hacer de M éxico un destino turístico competitivo e integral en su oferta y la entrega de ésta, se requiere lograr la uniformidad en la satisfacción de sus clientes, independientemente de su giro y tamaño. La capacitación de los directivos de los negocios turísticos es el primer paso que les permitirá conocer, comprender, aplicar y actualizarse en las formas de administrar que faciliten la satisfacción del cliente externo, garantizando así su permanencia en el mercado.

La planeación estratégica es una filosofía que permite aterrizar proyectos para disminuir y controlar los riesgos. Ésta lleva a la operatividad de todos los conceptos y enfoques que se han planteado y propuesto en este análisis; también es una herramienta excelente para trabajar el modelo de calidad total y lograr lo que plantea el PST 2007-2012: la satisfacción de todos sus elementos, tanto los internos como los externos. Por tal razón, 
este estudio consideró al modelo de calidad total, que incluye el control total de calidad y la mejora continua, como la estructura administrativa mediante la cual se decida implementar algunos de los conceptos mencionados, siempre y cuando las propuestas no se queden como tales, sino que se puedan implementar de manera efectiva.

Actualmente en M éxico el turismo genera beneficios de efecto directo a la sociedad, pero en forma aislada. Cuando forme parte de un proyecto integral de país, el efecto económico dará resultados directos e indirectos integrales, lo que requerirá una dirección para su justa distribución. El turismo, por su naturaleza, es altamente sensible, exige una planeación integral respecto de los demás actores de la economía, pues debe mantener una acción diaria que lo fortalezca para que verdaderamente se convierta en una actividad económica competitiva que redunde en beneficios permanentes para el país. Concebir al turismo sólo desde el aspecto económico lo limita, lo frena y lo subestima, como ocurre en la actualidad en M éxico.

Es necesario insistir en que el turismo no es la promoción en sí, dado que se requiere un trabajo previo de capacitación y adiestramiento para servuccir con calidad total antes de promover el producto o servicio-base (el qué), además de servuccir también la entrega o servicio de producto (el cómo); el gobierno no lo ha hecho y no lo incluye en su política para el turismo, no se avizora que tenga planes para trabajar en fortalecer una cultura empresarial turística donde la capacitación y el adiestramiento en competencias cuantitativas y cualitativas aseguren el producto M éxico como destino turístico competitivo. Como dice Karl Albrecht (1994b): necesitamos aprender cómo lo hacen los mejores.

Este proyecto propone el concepto de calidad total como herramienta conceptual para sistematizar funciones y operaciones en el sector turístico, identificando las partes que forman los procesos de servucción del qué y del cómo (M agaña, 2004: 2445), para satisfacer las necesidades y expectativas del clienteexterno, garantizando así los productos y el servicio turísticos nacionales. Para llevar a buen término lo anterior, es necesario tomar en cuenta la estructura del capital humano que participa en la organización, pues todos los individuos involucrados en la acción diaria de la empresa son quienes servuccen el producto y el servicio en el turismo, en virtud de que participan en una cantidad ilimitada de momentos de la verdad, independientemente de su nivel jerárquico. 
Durante el periodo estudiado, podemos observar que en los planes y programas sólo se incluye el recurso humano (así Ilamado por el gobierno) en la capacitación para aspectos operativos en el trabajo $y$, hasta ahora, no se ha considerado que primero es un capital de la empresa turística y, por ende, para el país mismo; no se ha tomado en cuenta para construir una estrategia basada en las personas que diseñan y servuccen el producto y el servicio turísticos, dado que son quienes también generan valor a estas dos dimensiones del servicio: el producto o servicio base (el qué) y la entrega o servicio (el cómo). Por tanto, es urgente promover una política pública turística que apoye la cultura empresarial para que exista el compromiso de parte de la alta dirección de la organización turística para trabajar por la competitividad desde el modelo de servir con calidad total.

En efecto, como se mencionó, para que la actividad turística tenga éxito requiere de la buena relación de los sectores que intervienen: el oficial (público gubernamental, en sus tres niveles), el productivo (la iniciativa privada), el social (organizaciones no gubernamentales, cámaras, asociaciones, etc.) y la academia (instituciones educativas).

M e permito agregar que el tiempo ofrece la oportunidad de ver claramente, de encontrarse con lo que no se puede percibir en esos momentos, cuando se tienen las inquietudes, la generación de ideas, durante la búsqueda de información, el análisis de ésta, y durante la construcción del nuevo conocimiento. Es por eso que la propuesta que hice en mi tesis doctoral (M agaña, 2004), en relación con el modelo de calidad en el servicio (como lo plantea Albrecht), ahora se nutre para plantear y proponer desde una concepción propia del modelo de servir con calidad total, el cual tiene como fundamento el ser como individuo, pues es quien decide qué y cómo hacer.

\section{Bibliografía}

Albrecht, Karl (1994a), La misión de la empresa, Paidós, Buenos Aires.

Albrecht, Karl (1994b), Todo el poder al cliente. El nuevo imperativo de la calidad del servicio, Paidós, Buenos Aires.

Baker, Dwayne A. y Daniel R. Fesenmaier (1997), “Effects of service climate on managers and employees rating of visi- 
tors service quality expectations", TTRA Journal of Travel Research, xxxvı, pp. 15-21.

Bounds, Greg, Lyle Yorks, M el Adams y Gipsie Ranney (1994), Beyond Total Quality Management. Towards the emerging paradigm, M cGraw H ill, N ueva York.

Bramwell, Bill y Angela Sharman (1999), "Colaboración en el diseño de políticas turísticas locales", Annals of Tourism, 1(1), Universitat de les Illes Balear, Palma de M allorca, pp. 120-146.

Centro de Estudios Sociales y de O pinión Pública (2006), Antecedentes, www.diputados.gob.mx/cesop/, actualización: 23 de marzo de 2006.

Centro de Estudios Sociales y de O pinión Pública (2006), Antecedentes, http://archivos.diputados.gob.mx/Centros_Estudio/ Cesop/Eje_tematico/2_turismo.htm, actualización: 23 de marzo de $\overline{2} 006$.

Daft, Richard (1998), O rganization Theory and Design, SouthWestern College Publishing, Cincinnati.

Drucker, Peter (1999), Thefrontiers of management. Wheretomorrow's decisions are being shaped today, Plume, N ueva York.

D rucker, Peter (2001), The essential Drucker. The best of sixty years of Peter D rucker's Essential Writings on Managements, $\mathrm{H}$ arper Business, $\mathrm{N}$ ueva York.

Elliott, James (1997), Tourism politics and public sector management, Routledge, Londres.

García, Esteban y Coll Serrano (2003), "Competitividad y eficiencia", Estudios de Economía Aplicada, Asociación de Economía Aplicada, 21 (3), M adrid, pp. 423-450.

Gobierno Federal (2000), Plan N acional de Desarrollo 2001-2006, M éxico. 
H itt, M ichael, Duane Ireland y Robert H oskisson (2004), Administración estratégica, Thomson, Buenos Aires.

Ivars-Baidar, J osep (2003), "Política local y gestión de los espacios turísticos", en La geografía y la gestión del turismo, vIII Coloquio de Geografía de Turismo, O cio y Recreación, Santiago de Compostela, noviembre de 2002, Universidad Santiago de Compostela, Galicia, pp. 17-55.

Jiménez, Alfonso (1993), Turismo. Estructura y desarrollo, $\mathrm{M}$ cG raw H ill, M éxico.

Juran, J oseph M. y Frank Gryna, (1995), Análisis y planeación de la calidad, M cGraw Hill, M éxico.

Juran, Joseph M . (1990), Juran y la planificación para la calidad, Díaz de Santos, M adrid.

López-Palomeque, Francisco (2004), “La ley del turismo de Cataluña, un nuevo instrumento en la evolución de la política turística", Cuadernos G eográficos, 34, G ranada, España, pp. 33-53.

M agaña, Irma (2004), Propuesta para implementar la cultura de servicio de calidad total en los negocios turísticos, tesis doctoral, publicada en línea por la Universidad de Colima, http://digeset.ucol.mx/tesis_posgrado/Pdf/Irma_ M agana_Carrillo.pdf.

M agaña, Irma (2005), El modelo de servir con calidad total: una estrategia para el mercado turístico mexicano, memoria publicada en línea, http://www.sectur.gob.mx/wb2/sectur/ sect_VIII_Congreso_Nacional_y_2_Internacional_de_I. VII Congreso Naciōnal y II Naciōnal de Investigación Turística, Cestur.

M éndez, José Silvestre (1998), Problemas económicos de México, M cG raw Hill, M éxico.

M onfort, Vicente (2000), "La política turística: una aproximación", Cuadernos de Turismo, 6, M urcia, pp. 7-27. 
Picazo, Luis y Fabián M artínez (1991), Ingeniería de servicios, M cGraw Hill, M éxico.

Porter, M ichael (1996), Estrategia competitiva. Técnicas para el análisis de los sectores industriales y de la competencia, CECSA, M éxico.

Porter, M ichael, Klaus Schwab y X avier Sala-I-M arti (eds.) (2007), The Global Competitiveness Report, World Economic Forum-M acmillan, $\mathrm{H}$ ampshire.

Sectur (Secretaría de Turismo) (2001), Programa Nacional de Turismo 2001-2006, Secretaría de Turismo, M éxico.

Sector (Secretaría de Turismo) (2004), L ey Federal de Turismo, http://www.sectur.gob.mx/wb2/sectur/sect_233_ley_ federal_de_turis.

Sectur (Secretaría de Turismo) (2007), Programa Sectorial de Turismo 2007-2012, Secretaría de Turismo, M éxico.

WAHAB (1992), "Goverment's role in Strategic Planning for Tourism", en M. K han et al. (eds.), Encyclopedia of Hospitality and Tourism, Van N ostrand Reinhold, N ueva York.

Walton, M ary (1992), Cómo administrar con el método Deming, Norma, Bogotá.

Recibido: 30 de octubre de 2006.

Reenviado: 11 de julio de 2008 Aceptado: 29 de septiembre de 2008

Irma M agaña Carrillo. Es doctora en ciencias en el área de relaciones internacionales y transpacíficas; maestra en administración y licenciada en administración de empresas turísticas con especialidad en planeación y promoción. $\mathrm{H}$ a hecho diplomados en desarrollo humano, calidad total, programación neurolingüística y consultoría industrial para sectores específicos. Actualmente es profesora-investigadora de tiempo completo en la Escuela de Turismo de la Universidad de Colima. Es perfil Promep 2009-2012. En 1994 hizo una especialidad en Industrial Engi- 
neering and Quality Control "Q uality M anagement" (Shu-SanRen) en N agoya, Japón, como Becaria de Agencia de Cooperación Internacional Japonesa. Fue directora de turismo del estado de Colima durante el gobierno de Griselda Álvarez. Durante 30 años ha sido empresaria turística; socia fundadora de la primera agencia de viajes del estado de Colima: Agencia de Viajes Tecnológico, S.A. de C.V. (Avitesa); socia fundadora de la empresa Reservaciones, Servicios y Viajes Prestigio, S.A. de C.V.; consultora en planeación estratégica, servir con calidad total y proyecto estratégico de vida. $\mathrm{H}$ a impartido 40 conferencias sobre modelo de calidad total, control total de calidad, sistemas de calidad, herramientas para medir la calidad cualitativa y cuantitativa, mejora continua, las 5S's planeación estratégica, entre otros. $\mathrm{Ha}$ dado 30 cursos sobre calidad, taller de calidad total, planeación estratégica, desarrollo humano integral y neurolingüística. $\mathrm{Ha}$ participado en seis investigaciones en el área de calidad en el servicio. $\mathrm{H}$ a recibido los siguientes reconocimientos: ocho como mejor alumna en la licenciatura; Premio Peña Colorada en la maestría en administración; mejor maestra del Tecnológico de Colima y en cuatro ocasiones en el Tecnológico de M onterrey, mejor profesora de grupo en la Facultad de Turismo de la Universidad de Colima. Coordinadora de dos libros académicos. Autora y coautora de 11 capítulos de libro. Autora de tres artículos indizados. Es experta en la filosofía de servir con calidad total y en metodología de servuccir con calidad total. 